\title{
Peran Pencahayaan Terhadap Suasana Ruang Interior Beehive Boutique Hotel Bandung
}

\author{
Risti Ramadhania Wulandari ${ }^{1}$, Tiara Isfiaty ${ }^{2}$ \\ ${ }^{1,2}$ Desain Interior, Fakultas Desain, Universitas Komputer Indonesia, Bandung \\ Email: ${ }^{1}$ risti.ramadhania@gmail.com, ${ }^{2}$ tiara.isfiaty@email.unikom.ac.id
}

\begin{abstract}
Abstrak: Penelitian ini bertujuan untuk mengetahui pengaruh dari peran pencahayaan untuk menciptakan suasana yang dapat menggambarkan tema atau penggayaan tertentu yang diterapkan pada desain ruang Beehive Boutique Hotel sehingga dapat terlihat, terasa, dan teramati visualisasinya oleh pengguna ruang atau pengamat ruang. Pencahayaan menjadi elemen yang penting untuk menghadirkan suasana serta karakter pada suatu ruang interior. Terdapat banyak jenis pencahayaan yang dapat diterapkan pada ruangan interior dan bergantung pada suasana apa yang ingin dirasakan oleh pengguna ruang. Pencahayaan juga dapat mendukung untuk menghadirkan visualisasi dari penggayaan yang diterapkan pada ruangan. Metode yang digunakan pada penelitian ini adalah pengamatan dan perbandingan berdasarkan teori yang dipakai pada penelitian. Hasil dan kesimpulan yang diambil dijelaskan secara deskriptif menurut pengamatan yang dilakukan peneliti dengan membandingkannya dengan teori yang dipakai. Kesimpulannya adalah bahwa peran pencahayaan yang diterapkan pada ruang interior Beehive Boutique Hotel dapat membantu menciptakan suasana yang menggambarkan tema atau penggayaan Skandinavia yang diterapkan pada interior hotel.
\end{abstract}

Kata kunci: Suasana, Pencahayaan, Penggayaan, Hotel

\begin{abstract}
This research aims to find out the influence of lighting roles to create an atmosphere that can describe a particular theme or styling applied to the design of the Beehive Boutique Hotel space so that it can be seen, felt, and observed visualized by space users or space observers. Lighting is an important element to bring atmosphere and character to an interior space. There are many types of lighting that can be applied to the interior room and depending on what atmosphere the user wants to feel. Lighting can also support visualization of the style applied to the room. The method used in this study is observation and comparison based on the theory used in the research. The results and conclusions drawn are described descriptively according to observations made by researchers by comparing them to the theory used. The conclusion is that the lighting role applied to the Beehive Boutique Hotel's interior space can help create an atmosphere that depicts scandinavian themes or sytles applied to the hotel's interior.
\end{abstract}

Keywords: Atmosphere, Lighting, Styling, Hotel 


\section{PENDAHULUAN}

Pencahayaan merupakan salah satu faktor penting dalam mendukung aktifitas manusia di dalam ruangan. Kualitas pencahayaan yang buruk dapat menghambat aktifitas manusia dan dapat mengakibatkan gangguan pada kesehatan mata. Maka dari itu, pencahayaan yang diterapkan pada suatu bangunan atau ruangan harus dipertimbangkan baik secara fungsi maupun kebutuhan agar pengguna ruang merasa nyaman saat menggunakan ruangan (Sari, 2017). Selain membantu dalam aktifitas manusia, ternyata pencahayaan juga dapat membantu memberikan efek estetika terhadap suatu ruangan. Pemakaian jenis pencahayaan, warna cahaya, bentuk, penempatan serta teknik yang dipakai pada pencahayaan mampu memberikan suasana serta karakter yang berbeda-beda terhadap ruangan. Maka sangat penting untuk memperhatikan pencahayaan seperti apa yang akan diterapkan pada ruangan untuk membantu menciptakan suasana dalam ruangan.

Memiliki tema atau penggayaan tertentu pada sebuah bangunan juga sangat penting untuk menciptakan suasana dalam ruang. Dalam membangun sebuah hotel apalagi jenis hotel butik penentuan tema atau penggayaan yang dipakai menjadi sangat penting karena ciri khasnya adalah memiliki tema untuk dijadikan pembeda dari hotel lainnya. Tema juga menjadi daya tarik utama untuk menarik perhatian pengunjung.

Melihat kedua hal penting di atas, peran pencahayaan menjadi sangat penting untuk menciptakan suasana yang menggambarkan sebuah penggayaan tertentu sehingga dapat terlihat, terasa dan teramati visualisasinya bagi pengguna ruang. Maka dari itu, jenis pencahayaan harus sesuai agar visualisasi dari penggayaan yang dipakai dapat tersampaikan dengan baik kepada pengguna ruang.

\section{METODE}

Penelitian ini bertujuan untuk mengetahui pengaruh dari peran pencahayaan untuk dapat memunculkan suasana tema atau penggayaan Skandinavia yang diterapkan pada desain ruang interior Beehive Boutique Hotel apakah dapat tersampaikan atau tidak kepada pengguna ruang atau pengamat ruang. Melalui metode pengamatan dan perbandingan berdasarkan teori yang dipakai pada penelitian. Hasil dan kesimpulan yang diambil akan dibuat secara deskriptif berdasarkan perbandingan teori yang dipakai dengan pengamatan yang dilakukan pada ruang interior Beehive Boutique Hotel.

Teori yang dipakai adalah menurut Fiqih (2020) dalam artikelnya berpendapat bahwa para desainer Skandinavia mengembangkan sebuah gagasan mengenai desain yang lebih mengutamakan unsur fungsional tanpa mengesampingkan unsur estetika dalam suatu ruang interior. Selain itu, salah satu ciri khas dari gaya Skandinavia dalam simpulan artikelnya menyebutkan penerapan bukaan yang besar menjadi sebuah trik untuk memberi kesan ruang menjadi lebih cerah, luas, dan nyaman. 


\section{HASIL DAN PEMBAHASAN}

\section{Pencahayaan}

Hidup manusia sangat bergantung pada cahaya, selain untuk mendukung berlangsungnya kegiatan sehari-hari, cahaya juga membantu manusia dalam segi penglihatan untuk mengenali segala warna, bentuk, dimensi, dan segala hal detail lainnya. Selain itu, cahaya juga membantu untuk menciptakan suasana dan karakter dalam sebuah ruang interior (Setiawan, 2014). Rencana pencahayaan yang benar dapat memberi kesan tersendiri pada desain interior (Pritchard, 1986).

Elemen yang penting dalam suatu ruang interior salah satunya adalah pencahayaan. Metode pencahayaan yang digunakan dapat berpengaruh terhadap mutu desain yang dihasilkan serta yang dapat dirasakan oleh pengguna ruang (Wijaya, 2017). Cahaya yang masuk dalam ruang interior memiliki tujuan untuk menyinari segala elemen yang terdapat pada ruang dalam sehingga suasana ruang menjadi terasa, teramati, serta terasa secara visual (Honggowidjaja, 2003). Banyak jenis dan teknik dalam menggunakan elemen pencahayaan yang dapat diterapkan pada ruang interior sehingga dapat menghasilkan suatu visual yang diinginkan. Seorang penulis buku berjudul Lighting (2006: 8) bernama Akmal berpendapat bahwa ilmu tentang cahaya dan penataannya yang benar akan mengakomodasi dalam mengetahui sumber cahaya, pemilihan sumber cahaya buatan yang tepat sesuai kebutuhan, dan lebih baik bila menerapkan sendiri teknik penataan cahaya dalam ruang interior (Azis \& Handoko, 2014). Pencahayaan terbagi menjadi dua menurut sumbernya, yaitu pencahayaan alami dan pencahayaan buatan.

\section{1) Pencahayaan Alami}

Sumber pencahayaan alami yang paling utama bagi manusia adalah sinar matahari. Cahaya matahari memiliki kelebihan serta kekurangan dalam segi bidang interior. Kelebihannya adalah cahaya matahari bersifat alamiah atau natural, cahayanya tersedia dalam jumlah yang tidak memiliki batas tertentu, serta bersifat dinamis (Chandra \& Amin, 2013). Sedangkan kekurangannya adalah memiliki sifat yang tidak menentu, ketersediaan tergantung pada cuaca dan iklim, jumlah yang tidak dapat diatur, kandungan sinar violet di dalamnya dapat merusak material dengan tingkat kepekaan tertentu serta membawa panas ke dalam ruang interior (Honggowidjaja, 2003).

Di luar mengenai kekurangan dan kelebihan yang dimiliki sinar matahari, sumber satu-satunya pencahayaan alami tetap dapat diolah dengan baik apabila cara pengolahannya benar. Cahaya matahari bisa diolah dengan berbagai macam cara untuk bisa sampai ke dalam ruang interior. Misal dengan penerapaan bukaan seperti ventilasi, jendela, atau bukaan pada langit-langit atau atap. Selanjutnya dengan penambahan material tertentu seperti tirai, kaca film, atau bidang yang disusun secara teratur untuk segi keamanan dapat memberikan efek dan dampak tertentu pada ruang interior. Berbagai macam cara untuk mengolah sumber pencahayaan 
alami yaitu sinar matahari, bukan semata-mata hanya untuk memenuhi segi estetika saja, melainkan juga untuk memenuhi segi fungsi sebagai sarana penting bagi keberlangsungan kegiatan di dalam ruangan (Honggowidjaja, 2003). Selain itu, cahaya matahari menjadi pencahayaan yang patut disyukuri karena dengan keberadaannya, manusia dapat bekerja dengan baik dengan pencahayaan alami tersebut (Karlen \& Benya, 2007).

\section{2) Pencahayaan Buatan}

Pencahayaan buatan merupakan pencahayaan yang bukan berasal dari cahaya matahari melainkan buatan manusia (lampu). Pencahayaan buatan dalam penerapannya dapat berfungsi sebagai sumber penerangan untuk mendukung kegiatan sehari-hari serta berfungsi sebagai nilai estetika pada suatu ruangan (Setiawan, 2014).

Pencahayaan buatan memiliki makna yaitu bertujuan untuk membentuk suasana di dalam ruang interior bukan hanya sekedar menyediakan cahaya buatan seperti lampu dan penerangannya. Maka dari itu, pencahayaan buatan bukan hanya sekedar masalah praktis melainkan juga estetis. Dari sudut pandang nilai estetika memilih bentuk, jenis, warna, dan penempatan lampu menjadi sebuah pekerjaan yang memiliki unsur permainan yang menyenangkan. Dampak dan efek yang ditimbulkan oleh permainan lampu dapat melebihi apa yang diharapkan. Bukan hanya memberi penerangan untuk keberlangsungan kegiatan aktifitas, namun lampu juga bisa menghadirkan suasana yang nyaman bagi pengguna di dalam ruang interior (Chandra \& Amin, 2013).

Menurut Rees dalam bukunya berjudul Lighting Styles tahun 1999, pencahayaan buatan terbagi menjadi beberapa tipe, yaitu:

\section{a. Ambient Lighting atau General Lighting}

Merupakan pencahayaan yang paling umum. Jenis pencahayaan ini berasal dari sumber cahaya yang memiliki kapasitas cukup besar dan sinarnya mampu menerangi secara keseluruhan ruang interior.

\section{b. Task Lighting}

Merupakan pencahayaan yang bertujuan untuk membantu menerangi setiap proses kegiatan yang bersifat khusus yang dilakukan oleh pengguna ruang. Dibutuhkan untuk mempermudah memperjelas suatu pekerjaan yang bersifat spesifik. Biasanya dilakukan dalam sebuah ruang seperti bekerja dan menulis. Jenis pencahayaan ini dikatakan baik apabila dapat memperjelas pandangan, tidak membuat mata lelah dan membantu untuk lebih fokus terhadap aktifitas yang dilakukan.

\section{c. Accent Lighting}

Merupakan jenis pencahayaan yang bertujuan untuk mengekspos suatu area tertentu atau benda tertentu yang tidak mempunyai fungsi yang perlu 
ditunjukan. Bisa juga berguna untuk menerangi suatu objek seperti lukisan, benda seni, rak, dan sebagainya. Dalam lingkup interior jenis pencahayaan ini lebih banyak dipakai untuk memunculkan unsur estetika daripada unsur fungsional sebagai alat penerangan.

\section{d. Decorative Lighting}

Selain berfungsi untuk menerangi sebuah ruangan jenis pencahayaan ini juga berguna sebagai unsur dekoratif dalam tatanan ruang interior. Hal ini bisa dilihat dari bentuk-bentuk jenis pencahayaan ini. Biasanya memiliki desain yang memukau dan memiliki ukuran tertentu. Unsur estetika adalah daya tarik andalan dari jenis pencahayaan ini (Azis \& Handoko, 2014).

\section{3) Teknik Pencahayaan pada Ruang Interior}

Teknik pencahayaan tidak hanya menghasilkan sebuah efek cahaya, namun juga menciptakan suasana serta kualitas dari sebuah ruang (Martin, 2010). Dalam buku berjudul Lighting (2006 : 34) oleh Akmal menjelaskan bahwa terdapat beberapa teknik standar dalam penerangan untuk ruang interior, yaitu :

\section{a. Direct Lighting}

Disebut sebagai pencahayaan langsung. Teknik ini ditempatkan pada area dimana pencahayaan dapat langsung menerangi ruang interior tanpa bantuan media lain. Teknik ini dilakukan untuk ruang interior yang membutuhkan kualitas cahaya yang cukup terang dan biasanya lebih menonjolkan bentuk lampu yang digunakan.

\section{b. Indirect Lighting}

Disebut sebagai pencahayaan tidak langsung. Teknik ini ditempatkan pada area yang tidak terlihat oleh pengguna ruang interior. Biasanya menempatkan sumber cahaya secara tersembunyi, sehingga yang terlihat hanya sebuah pentulan cahaya bukan langsung dari sumber lampu. Teknik pencahayaan ini menimbulkan efek yaitu bersih dan sederhana.

\section{c. Downlight}

Teknik pencahayaan jenis ini berfungsi menerangi ruang interior dengan sumber cahaya berasal dari atas dan menerangi apa yang berada di bawah. Cahaya yang ditimbulkan memiliki sifat merata. Teknik downlight mempunyai intensitas cahaya yang cukup tinggi sehingga dijadikan sebagai segi pengukuran umur suatu ruang interior. Adapun intensitas cahayanya yang kecil digunakan sebagai accent lighting

\section{d. Uplight}

Teknik pencahayaan jenis ini berfungsi menerangi yang sumber cahayanya 
berasal dari arah bawah dan dipancarkan ke arah atas. Teknik ini dipakai pada jenis penerangan indirect lighting agar tidak mengganggu penglihatan. Teknik pencahayaan ini menimbulkan efek yang hasilnya lebih dominan untuk menunjukan kepentingan unsur estetika dan memberikan citra mewah dan eksklusif pada ruang interior.

e. Sidelight

Teknik pencahayaan jenis ini berfungsi sama dengan sebelumnya namun, sumber cahayanya mengarah ke samping baik dari kiri ke kanan maupun dari kanan ke kiri atau bisa jadi dari arah keduanya. Biasanya menerangi suatu objek atau berfungsi untuk mengekspos sehingga menimbulkan fokus pada penerangan atau memunculkan tekstur material terhadap objek yang diterangi.

\section{f. Frontlight}

Teknik pencahayaan ini, sumber cahayanya muncul secara horizontal. Penerapan teknik pencahayaan semacam ini berguna untuk menerangi sebuah benda yang memiliki unsur seni dua dimensi, contohnya lukisan.

\section{g. Backlight}

Teknik backlight secara fungsional sangat berbeda dari frontlight. Apabila frontlight memanfaatkan cahaya untuk menerangi objek yang tampak, sedangkan backlight memanfaatkan area belakang objek atau unsur bayangan yang tercipta dari objek untuk ditampakkan kepada pengguna ruang. Jadi efek bayangan dari objeklah yang dijadikan fokus utama dalam penerangan teknik ini.

\section{Penggayaan Skandinavia}

Penggayaan Skandinavia pertama kali muncul pada awal abad ke-20 yang akhirnya menyebar di tahun 1950-an. Pada masa tersebut, para desainer yang berasal dari berbagai negara di Eropa mempunyai tujuan untuk memberi berbagai gagasan baru yang inovasi dan modern untuk dijadikan tren di era selanjutnya. Kemudian mulailah para desainer Skandinavia untuk mengembangkan suatu gagasan desain yang lebih mementingkan segi fungsional, namun tetap tidak mengesampingkan unsur estetika dari sebuah produk desain.

Tidak begitu lama setelah tahun tersebut, konsep gaya arsitektur Skandinavia mulai diperkenalkan melalui pameran desain yang diadakan. Salah satu pamerannya adalah exhibition Design in Scandinavia yang dilakukan oleh Museum Brooklyn pada tahun 1954. Salah satu yang menjadi hal utama yang terus diperkenalkan oleh para desainer Skandinavia adalah cara hidup orang-orang mereka yang mengedepankan unsur keindahan, kesederhanaan, dan ide desain yang terkesan bersih (Fiqih, 2020). 
Menurut Fiqih (2020) dalam artikelnya menyebutkan simpulan beberapa poin yang menjadi ciri khas pada gaya desain Scandinavia, yaitu:

1) Sangat erat hubungannya dengan alam

Salah satu material alami yang sering diterapkan untuk memenuhi kebutuhan interior maupun ekterior adalah material kayu. Unsur kayu memberi kesan alami dan menimbulkan suasana yang hangat.

2) Mengutamakan unsur fungsional dan unsur estetika

Ciri yang paling menonjol dalam gaya Skandinavia adalah mengutamakan dalam segi fungsi dan nilai estetika.

3) Mengoptimalkan penataan letak furnitur

Untuk mendapatkan suasana yang nyaman, penataan letak furnitur yang optimal dapat memberi sirkulasi yang luas untuk ruang gerak bagi pengguna ruang interior. Pengoptimalan tata letak furnitur dapat menciptakan ruang yang terkesan rapih dan sederhana.

4) Menerapkan bukaan yang besar

Salah satu ciri khas utama lainnya dalam gaya Skandinavia adalah penerapan bukaan yang besar. Hal ini dijadikan rahasia kecil untuk menjadikan rumah khas Skandinavia terlihat sangat terang, luas, dan nyaman.

5) Warna netral menjadi warna yang mendominasi

Warna yang selalu diterapkan dalam konsep gaya desain Skandinavia adalah warna putih, abu- abu, dan krem. Warna netral mendominasi dalam gaya ini dikarenakan kemampuan warna netral yang menjadikan ruang interior terkesan lebih terang, luas dan nyaman.

\section{Ruang Interior}

Desain interior merupakan proses dari perencanaan, penataan, dan perancangan ruang interior dalam sebuah bangunan. Menurut D.K Ching pengertian ruang merupakan bahan utama bagi seorang perancang dan unsur utama dalam bidang desain interior (Fatimah, Derwentyana, \& Maharlika, 2015).

Elemen interior yang disebutkan oleh Ching (1996) meliputi antara lain:

1) Lantai

2) Dinding

3) Langit-langit 
4) Sirkulasi

5) Penghawaan

6) Mebel

7) Pencahayaan

\section{Hotel}

Pengertian hotel menurut Lawson (1976) merupakan sebuah fasilitas umum berupa tempat tinggal untuk para wisatawan dengan menyediakan jasa pelayanan berupa kamar, kebutuhan pangan, serta sarana yang memerlukan pembayaran lebih sebagai syarat (Suwarno, Laksmitasari, \& Widyawati, 2017).

\section{Hotel Butik}

Menurut Anhar, hotel butik memiliki pemahaman sebagai hotel dengan orisinilitas. Hotel butik memiliki konsep tertentu dan menjadikannya hotel dengan identitas yang kuat (Dian, 2017).

\section{Objek Penelitian}

Beehive Boutique Hotel merupakan salah satu hotel jenis butik yang berlokasi di Bandung. Lokasinya tidak jauh dari komplek Kampus ITB dan letaknya berdekatan dengan beberapa café di daerah Dago. Bangunan hotel terdiri dari lima lantai dan menerapkan konsep Skandinavia. Hotel tersebut menyediakan lima tipe kamar dan dua diantaranya yang paling diminati. Alasan paling banyak dinikmati adalah kamarnya yang menyediakan pemandangan bergaya rooftop. Memiliki atap dengan bukaan jendela yang memiliki kaca berukuran besar dengan sudut yang miring. Jenis kamar tersebut menjadi incaran para pengunjung hotel karena ingin merasakan sensasi menginap dalam suasana Instagenic. Selain di kamar hotel yang menerapkan bukaan jendela yang besar, area lobby pun dikelilingi jendela kaca yang besar sehingga menghasilkan pencahayaan alami yang maksimal.

Dengan menerapkan bukaan jendela yang besar hal ini membuktikan bangunan hotel mengandalkan pencahayaan alami secara maksimal. Berikut beberapa bukti foto dari Beehive Boutique Hotel yang menunjukkan bangunannya mengandalkan pencahayaan alami secara maksimal. 


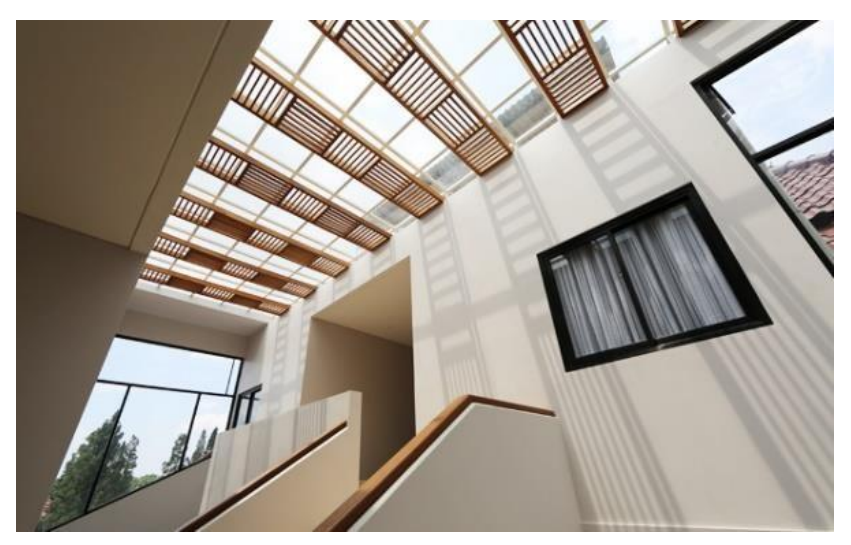

Gambar 1. Atap yang menerapkan material kaca Sumber: beehivebdg.com, 2020

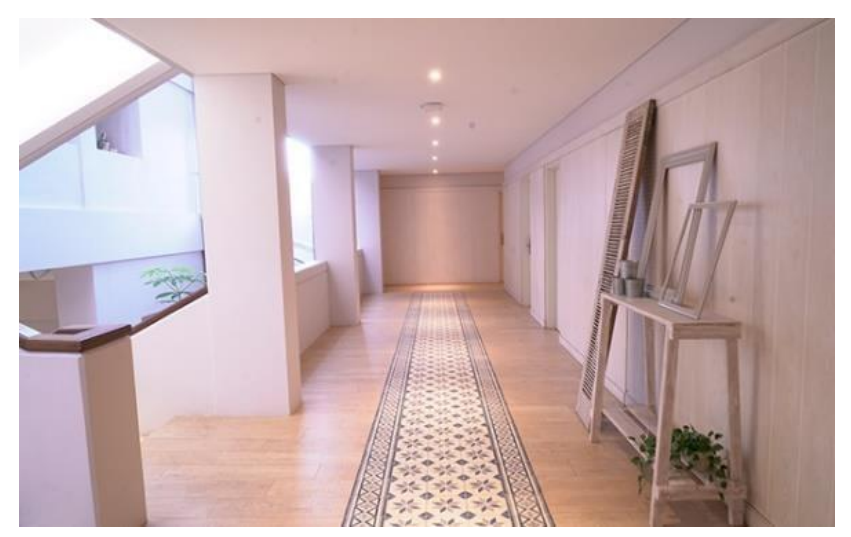

Gambar 2. Suasana area koridor kamar hotel Sumber: beehivebdg.com, 2020

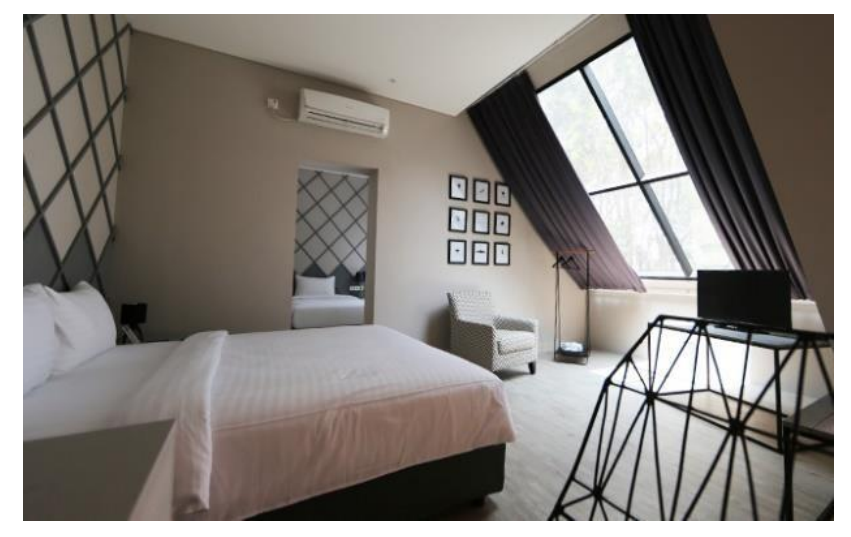

Gambar 3. Interior kamar hotel dengan bukaan jendela besar dengan sudut yang miring Sumber: beehivebdg.com, 2020 


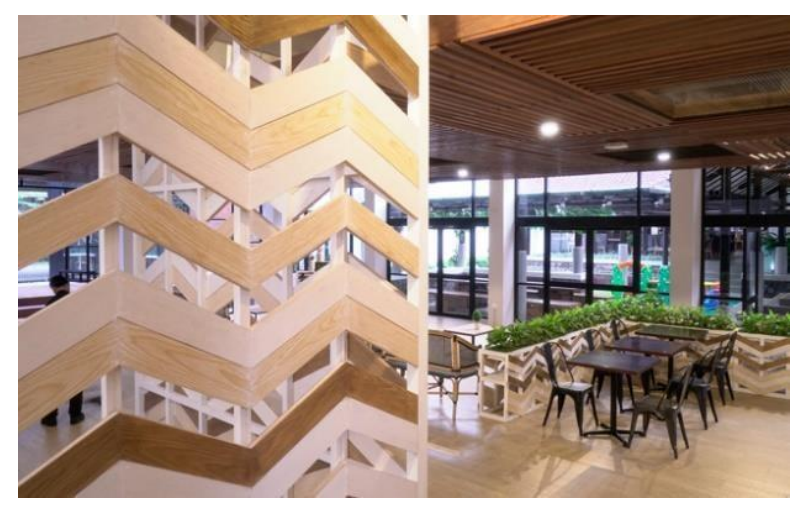

Gambar 4. Interior restoran dalam hotel Sumber: beehivebdg.com, 2020

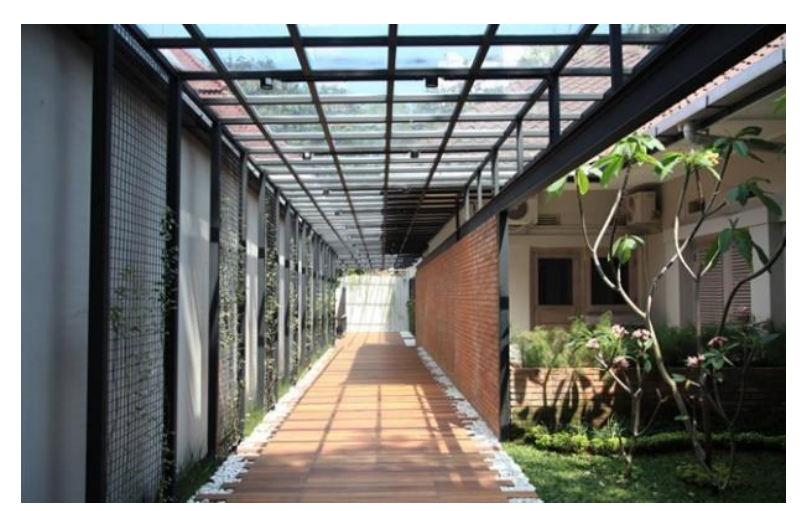

Gambar 5. Interior koridor hotel Sumber: beehivebdg.com, 2020

Dari beberapa gambar di atas terlihat hampir seluruh ruangan interior hotel Beehive Boutique Hotel banyak mengandalkan cahaya alami untuk menerangi tiap ruangan. Selain mengandalkan cahaya alami Beehive Boutique Hotel juga pasti mengandalkan cahaya buatan. Berikut beberapa foto yang memperlihatkan suasana interior hotel yang mengandalkan cahaya buatan.

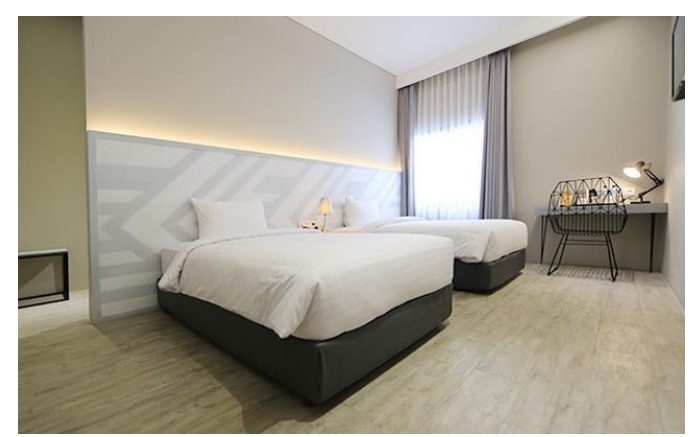

Gambar 6. Interior kamar hotel Sumber: beehivendg.com, 2020 


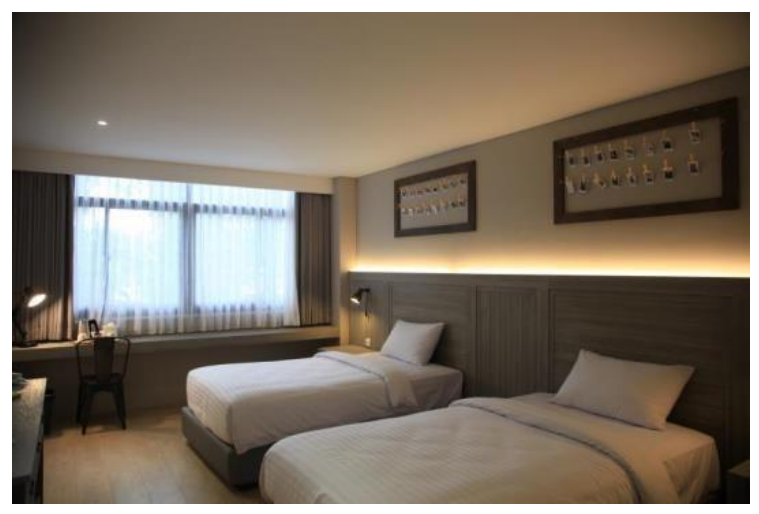

Gambar 7. Interior kamar hotel

Sumber: beehivebdg.com, 2020

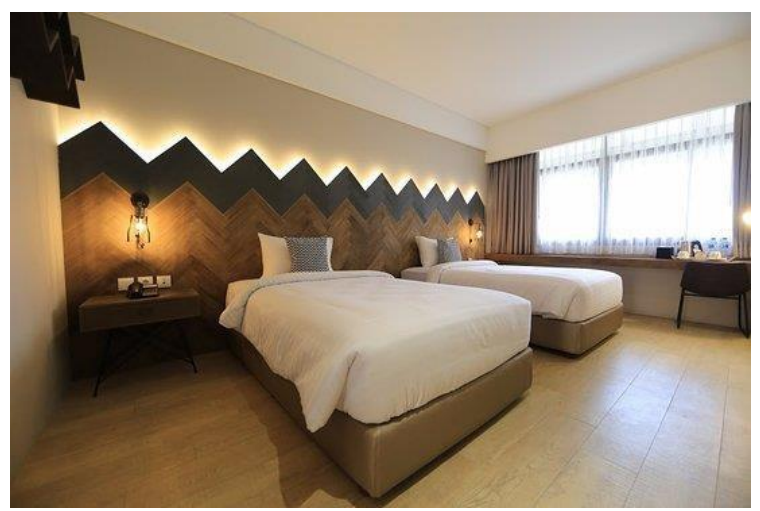

Gambar 8. Interior kamar hotel

Sumber: beehivebdg.com, 2020

Pada gambar 6, gambar 7, dan gambar 8 interior kamar hotel lebih mengandalkan pencahayaan buatan dibanding pencahayaan alami. Pencahayaan buatan yang dipakai diantaranya task lighting, accent lighting, dan general lighting dengan teknik pencahayaan yang berbeda.

Untuk jenis task lighting terlihat pada penggunaan lampu pada meja kerja dan lampu pada nakas. Warna lampu yang dipakai adalah warm white. Bila diamati, ruang kamar interior banyak menerapkan material dengan aksen kayu. Kayu adalah material yang memiliki kesan yang hangat. Dengan warna lampu warm white yang terlihat berwarna oren redup menambah kesan hangat pada ruang interior.

Untuk jenis accent lighting dengan teknik indirect terlihat pada penggunaan lampu LED strip yang dipasang pada back drop tempat tidur atau treatment dinding yang ada di belakang tempat tidur. Dengan warna lampu yang dipakai adalah warm white. Penggunaan lampu jenis ini bila diamati hanya berfungsi sebagai dekoratif untuk mendukung estetika dari bentuk treatment dinding yang sedemikian rupa. 
Sedangkan general lighting dengan teknik downlight terlihat pada langit-langit ruangan. Dengan warna lampu cool white. Menggambarkan suasana yang berbeda dan fungsi yang berbeda pula. Lampu jenis ini bila diamati, berfungsi sebagai penerangan utama untuk menerangi secara menyeluruh maka dari itu dipakai warna cool white agar penerangan tidak terlalu redup dan ruangan menjadi terlihat jelas.

\section{KESIMPULAN}

Berdasarkan pengamatan yang telah dilakukan dapat disimpulkan bahwa peran pencahayaan yang diterapkan pada ruang interior Beehive Boutique Hotel dapat membantu menciptakan suasana yang menggambarkan tema atau penggayaan Skandinavia yang diterapkan pada interior hotel. Terlihat pada pencahayaan yang diterapkan dalam bangunan. Beehive Boutique Hotel banyak mengandalkan pencahayaan alami yang datang dari bukaan jendela yang besar. Diketahui salah satu ciri khas dari penggayaan Skandinavia adalah menerapkan bukaan jendela yang besar. Hal ini berguna untuk memberikan suasana ruang yang luas, cerah, dan nyaman. Selain itu pencahayaan buatan yang diterapkan dalam ruang interior ditempatkan sesuai dengan fungsi masing-masing dan tidak terlalu berlebihan atau mencolok. Berkat minimnya penerapan cahaya buatan yang hanya menambah kesan estetika suasana yang menggambarkan penggayaan atau tema Skandinavia dapat terlihat dan terasa oleh pengamat. Diketahui bahwa penggayaan Skandinavia lebih mengutamakan unsur fungsional agar dapat menciptakan ruangan yang terlihat sederhana dan terasa luas karena minimnya penggunaan furnitur dan tata letaknya yang diatur sedemikian rupa agar sirkulasi menjadi luas.

\section{DAFTAR PUSTAKA}

Akmal, I. (2006). Lighting. Jakarta: PT. Gramedia Pustaka Utama.

Azis, A. R., \& Handoko, B. (2014). Desain Pencahayaan Buatan pada Proses Relaksasi Pengguna Pusat Kebugaran. Jurnal Tingkat Sarjana Bidang Senirupa dan Desain No. 1, 2-10.

Chandra, T., \& Amin, A. Z. (2013). Simulasi Pencahayaan Alami dan Buatan dengan Ecotect Radiance pada Studio Gambar. Jurnal Arsitektur Komposisi, Vol. 10, No. 3, 171-181.

Ching. (1996). Ilustrasi Desain Interior. Jakarta: Erlangga.

Dian. (2017). Hotel Butik Di Kota Singkawang. Jurnal Online Mahasiswa Arsitektur Universitas Tanjungpura, 50-63.

Fatimah, D., Derwentyana, R., \& Maharlika, F. (2015). Studi Evaluasi Penerapan Mata Kuliah Nirmana I \& II pada Tugas Perancangan Mahasiswa Prograam Studi Desain Interior Unikom. Majalah Ilmiah UNIKOM Vol. 13 No. 2, 129-136. 
Fiqih, E. A. (2020, April 2). Mengenal Lebih Dalam Gaya Desain Interior Skandinavia. Retrieved from InteriorDesign.id: https://interiordesign.id/

Honggowidjaja, S. P. (2003). Pengaruh Signifikan Tata Cahaya pada Desain Interior. Dimensi Interior , 1-15.

Karlen, M., \& Benya, J. (2007). Dasar-dasar Desain Pencahayaan. Jakarta: Erlangga.

Martin, L. (2010). The Lighting Bible. Singapore: Page One.

Pritchard, D. C. (1986). Interior Lighting Design. London: Lighting Industrial Federation Limited and The Electricity Council.

Rees, S. (1999). Lighting Styles. London: Octopus Publishing Group Limited.

Sari, T. P. (2017). Kontribusi Skylight Terhadap Performa Pencahayaan Alami Greenhost Boutique Hotel di Yogyakarta. Prosiding Seminar Nasional Energi Efficient for Sustainable Living, 45-61.

Setiawan, B. (2014). Pencahayaan Buatan pada Pendekatan Teknis dan Estetis untuk Bangunan dan Ruang Dalam. Humaniora Vol. 5 No.2, 1222-1233.

Suwarno, Y., Laksmitasari, R., \& Widyawati, K. (2017). Perancangan Hotel Bintang Tiga dengan Konsep Hospitality di Jakarta Selatan. Jurnal Desain, 53-60.

Wijaya, I. I. (2017). K153-Teknik Optimasi Pencahayaan Alami dalam Interior Rumah Tinggal. Simposium Nasional RAPI XVI FT UMS, 377-384. 